\section{Case Reports in Gastroenterology}

Case Rep Gastroenterol 2016;10:193-198

\title{
Recovery from Choriocarcinoma Syndrome Associated with a Metastatic Extragonadal Germ Cell Tumor Hemorrhage
}

\author{
Koji Komori ${ }^{a}$ Daisuke Takahari ${ }^{b, c}$ Kenya Kimura ${ }^{a}$ Takashi Kinoshita $^{a}$ \\ Seiji Ito $^{a}$ Tetsuya Abe ${ }^{a}$ Yoshiki Senda $^{a}$ Kazunari Misawa ${ }^{a}$ \\ Yuichi Ito $^{a}$ Norihisa Uemura $^{a}$ Seiji Natsume ${ }^{a}$ Jiro Kawakami ${ }^{a}$ \\ Yoshinori Iwata $^{a}$ Masayuki Tsutsuyama $^{a}$ Itaru Shigeyoshi ${ }^{a}$ \\ Tomoyuki Akazawa $^{a}$ Daisuke Hayashi ${ }^{\mathrm{a}}$ Akira Ouchi $^{\mathrm{a}}$ \\ Yasuhiro Shimizu ${ }^{a}$ \\ ${ }^{a}$ Department of Gastroenterological Surgery, Aichi Cancer Center Hospital, \\ Nagoya, Japan; ${ }^{b}$ Department of Clinical Oncology, Aichi Cancer Center Hospital, \\ Nagoya, Japan; 'Department of Gastroenterology, Cancer Institute Hospital of the \\ Japanese Foundation for Cancer Research, Tokyo, Japan
}

\section{Keywords}

Extragonadal germ cell tumor · Choriocarcinoma syndrome

\begin{abstract}
A germ cell tumor is the most common form of malignancy in early male life, and can be classified as either seminomatous or nonseminomatous. Choriocarcinoma, comprised of nonseminomatous germ cells, is the most aggressive type of germ cell tumor and characteristically metastasizes to the retroperitoneal lymph nodes and less frequently to the lungs, liver, bone or brain [Shibuya et al., 2009;48:551-554]. A 56-year-old man was admitted to another hospital complaining of abdominal distension. Symptoms included anorexia, vomiting, and diarrhea. The patient was diagnosed with an extragonadal germ cell tumor and referred to our hospital to receive chemotherapy. The day after admission, the patient's abdominal distension gradually worsened. An emergency operation revealed venous hemor-
\end{abstract}


rhage from the surface of a metastatic extragonadal germ cell tumor between the ligament of Treitz and the inferior mesenteric vein in a horizontal position. Hemostatic treatment was performed with 4-0 proline thread attached to a medicated cotton sponge, rather than using a simple proline thread, and the closure area was manually compressed. Chemotherapy was initiated on postoperative day 10. A metastatic extragonadal germ cell tumor that causes massive hemorrhage and gastrointestinal hemorrhage is very rare, and represents a lifethreatening emergency. If the patient's condition carries a substantial risk of bleeding to death, it may be worthwhile to attempt abdominal operations.

(C) 2016 The Author(s)

Published by S. Karger AG, Basel

\section{Introduction}

Germ cell tumors are the most common form of malignancy in men between the ages of 15 and 35 years treated by urologists, and characteristically metastasize to the retroperitoneal lymph nodes and less frequently to the lungs, liver, bone or brain [1]. A metastatic extragonadal germ cell tumor that causes massive hemorrhage and gastrointestinal hemorrhage is very rare, and represents a life-threatening emergency [2]. This condition is termed choriocarcinoma syndrome (CS) in advanced germ cell tumors with high-volume choriocarcinomatous elements $[3,4]$. One of the standard chemotherapies for advanced germ cell tumors is BEP (bleomycin, etoposide, and cisplatin), which, however, has serious adverse effects, such as CS [5]. Luckily, such choriocarcinomatous elements are rare among operative cases of metastatic extragonadal germ cell tumors that cause massive hemorrhage. We herein report the case of a patient who recovered from CS associated with a metastatic extragonadal germ cell tumor with massive hemorrhage such that the patient was subsequently able to undergo chemotherapy. Operative hemostatic treatment was performed precisely and quickly with 4-0 proline thread attached to a medicated cotton sponge.

In particular, we herein report on the surgical technique of hemostatic treatment during an emergency operation.

\section{Case Report}

The patient was a 56-year-old man who was admitted to another hospital complaining of abdominal distension. A percutaneous needle biopsy was performed. The patient was diagnosed with an extragonadal germ cell tumor and referred to our hospital to receive chemotherapy. The patient had considerably high human chorionic gonadotropin $(4,100$ $\mathrm{ng} / \mathrm{ml})$ and $\alpha$-fetoprotein $(149.7 \mathrm{ng} / \mathrm{ml})$ levels. A computed tomography (CT) scan performed upon admission showed that the irregular marginal tumor of about $4 \mathrm{~cm}$ in width contained necrotic tissue in the central space (fig. 1) as well as a solitary liver metastasis and multiple lung metastases. The next day, the patient's abdominal distension gradually worsened. The patient's systolic blood pressure was low (approximately $60 \mathrm{~mm} \mathrm{Hg}$ ), and his general condition deteriorated. The patient underwent CT examinations that showed hemoperitoneum from a metastatic extragonadal germ cell tumor (fig. 2) and multiple lung metastases (fig. 3). An emergency operation was performed. Venous hemorrhage from the surface of the metastatic extragonadal germ cell tumor was recognized between the ligament of Treitz and the inferior mesenteric vein in a horizontal position. A total of 2,200 $\mathrm{ml}$ of blood caused a hemorrhagic shock. The metastatic extragonadal germ cell tumor was very soft and fragile. 


\section{Case Reports in Gastroenterology}

Case Rep Gastroenterol 2016;10:193-198

(c) 2016 The Author(s). Published by S. Karger AG, Basel www.karger.com/crg

Komori et al:: Recovery from Choriocarcinoma Syndrome Associated with a Metastatic Extragonadal Germ Cell Tumor Hemorrhage

Therefore, hemostatic treatment was performed with 4-0 proline thread attached to a medicated cotton sponge rather than using a simple proline thread (fig. 4). Afterwards, the closure area was manually compressed for approximately $15 \mathrm{~min}$. Complete hemostasis was eventually confirmed. The operative time was $99 \mathrm{~min} ; 2,000 \mathrm{ml}$ of blood and 1,200 $\mathrm{ml}$ of fresh-frozen plasma were transfused. After the surgery, upon reevaluation using $\mathrm{CT}$, the lung metastases had become worse on postoperative day 9. The patient's general condition was nearly stable 10 days postoperatively, and etoposide $\left(70 \mathrm{mg} / \mathrm{m}^{2}\right)$ plus cisplatin $\left(20 \mathrm{mg} / \mathrm{m}^{2}\right)$ combination therapy was initiated. However, on postoperative day 25 , a massive gastrointestinal hemorrhage occurred, and an emergency endoscopic examination was performed. The apparent source of the hemorrhage was not detected because of massive coagulation in the gastrointestinal tract. The patient's general condition deteriorated drastically, and he subsequently died 1 month postoperatively. An autopsy was not performed.

\section{Discussion}

CS is the term for hemorrhages occurring at the site of metastasis in advanced germ cell tumors with high-volume choriocarcinomatous elements [2]. Motzer and Bosl [3] and Kobatake et al. [4] emphasized that CS is liable to occur in cases with significantly high human chorionic gonadotropin levels; tumor invasion into pulmonary small vessels can cause CS. Moreover, acute pulmonary hemorrhage is the most frequent manifestation of CS. Choriocarcinoma, which comprises nonseminomatous germ cells, is the most aggressive type of germ cell tumor [1].

Conversely, tumor lysis syndrome (TLS) has been described to occur much more frequently in hematological malignancies than in solid tumors, in which this complication is also rare. Among cases with TLS due to drug therapy, almost $90 \%$ had an onset within 2.0 days (median) after administration of the first cycle of treatment [5]. Whether the present case represented CS or TLS was difficult to determine, but the former was more likely.

Moore et al. [6] reported an operative case of retroperitoneal lymph node in a patient with a metastatic mixed germ cell tumor. In that case, persistent and profuse hemorrhage was controlled, and $90 \%$ of the metastases were resected. In our case, the metastatic extragonadal germ cell tumor was very bulky; thus, it was impossible to fully remove the tumor. However, the operative procedure was not previously described in detail. Accordingly, our report provides the first detailed description in terms of hemostatic treatment of CS from a metastatic extragonadal germ cell tumor. The dissemination of metastatic extragonadal germ cell tumors has not previously been described. However, care must be taken not to seed germ cell tumors from the fissure of the metastatic region.

Shibuya et al. [1] reported a rare case of gastrointestinal hemorrhage from a metastatic extragonadal choriocarcinoma that was similar to our case. In that case, the source of hemorrhage was detected in the stomach, and hemostasis was performed. In our case, gastrointestinal hemorrhage was suspected to be one of the causes of death. It was particularly fortunate that the hemostatic treatment was successfully performed, and the patient went on to receive chemotherapy, albeit with massive hemorrhage. I

This report describes a very rare case of a metastatic extragonadal germ cell tumor causing massive bleeding and gastrointestinal hemorrhage. If a patient's condition carries a substantial risk of bleeding to death, it may be worthwhile to attempt abdominal operations for hemostatic treatment. 


\section{Case Reports in Gastroenterology}

\begin{tabular}{l|l}
\hline $10.1159 / 000446017$ & $\begin{array}{l}\text { (c) } 2016 \text { The Author(s). Published by S. Karger AG, Basel } \\
\text { www.karger.com/crg }\end{array}$
\end{tabular}

Komori et al.: Recovery from Choriocarcinoma Syndrome Associated with a Metastatic Extragonadal Germ Cell Tumor Hemorrhage

\section{Statement of Ethics}

The published research is compliant with the guidelines for human studies and animal welfare regulations.

\section{Disclosure Statement}

All authors report no conflict of interest related to this paper.

\section{References}

1 Shibuya T, Osada T, Kodani T, Hojo, M, Saito, H, Ueyama, H, Kato, J, Nagahara, A, Otaka, M, Ogihara, T, Nagao, K, Fujime, M, Watanabe S: Gastrointestinal hemorrhage as the first manifestation of metastatic extragonadal choriocarcinoma. Intern Med 2009;48:551-554.

-2 Logothetis CJ, Samuels ML, Selig DE, Ogden, S, Dexeus, F, Swanson, D, Johnson, D, von Eschenbach A: Cyclic chemotherapy with cyclophosphamide, doxorubicin, and cisplatin plus vinblastine and bleomycin in advanced germinal tumors. Results with 100 patients. Am J Med 1986;81:219-228.

-3 Motzer RJ, Bosl GJ: Hemorrhage: a complication of metastatic testicular choriocarcinoma. Urology 1987;30:119-122.

4 Kobatake K, Kato M, Mita K: Advanced testicular cancer associated with life-threatening tumour lysis syndrome and choriocarcinoma syndrome. Can Urol Assoc J 2015;9:62-64.

-5 Taira F, Horimoto Y, Saito M: Tumor lysis syndrome following trastuzumab for breast cancer: a case report and review of the literature. Breast Cancer 2015;22:664-668.

-6 Moore K, Imbeault A, Roy G, Bolduc S: Massive hemorrhage from spontaneous rupture of a retroperitoneal lymph node in patient with metastatic mixed germ cell tumor. Urology 2010;76:159161.

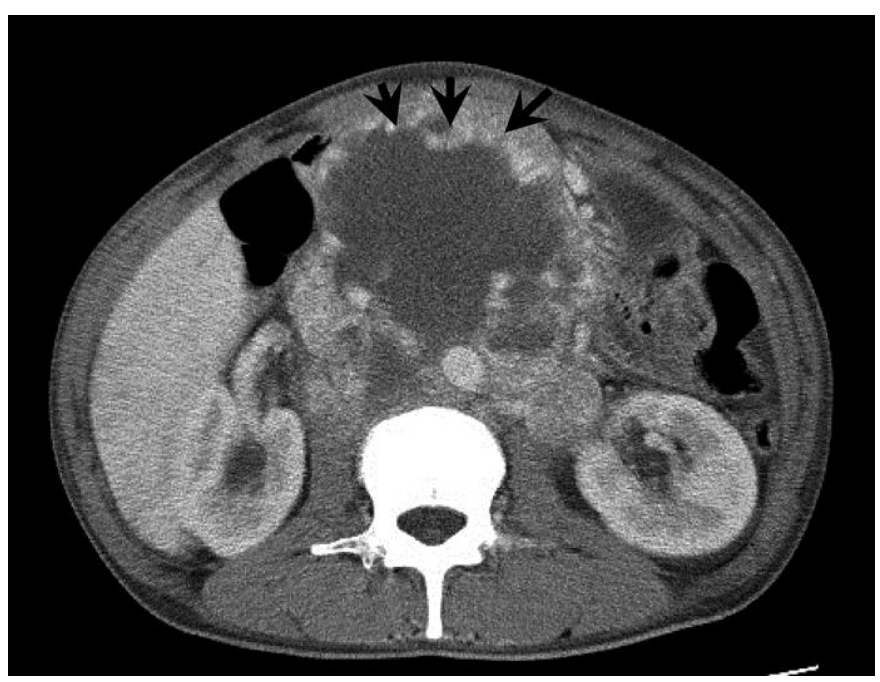

Fig. 1. An abdominal CT scan performed on admission showed that the irregular marginal tumor that was approximately $4 \mathrm{~cm}$ wide contained necrosis in the central space (black arrows). 


\section{Case Reports in Gastroenterology

\begin{tabular}{l|l}
\hline Case Rep Gastroenterol 2016;10:193-198 \\
\hline $10.1159 / 000446017$ & $\begin{array}{l}\text { ○ 2016 The Author(s). Published by S. Karger AG, Basel } \\
\text { www.karger.com/crg }\end{array}$ \\
\hline
\end{tabular} \\ Komori et al.: Recovery from Choriocarcinoma Syndrome Associated with a Metastatic Extragonadal Germ Cell Tumor Hemorrhage}

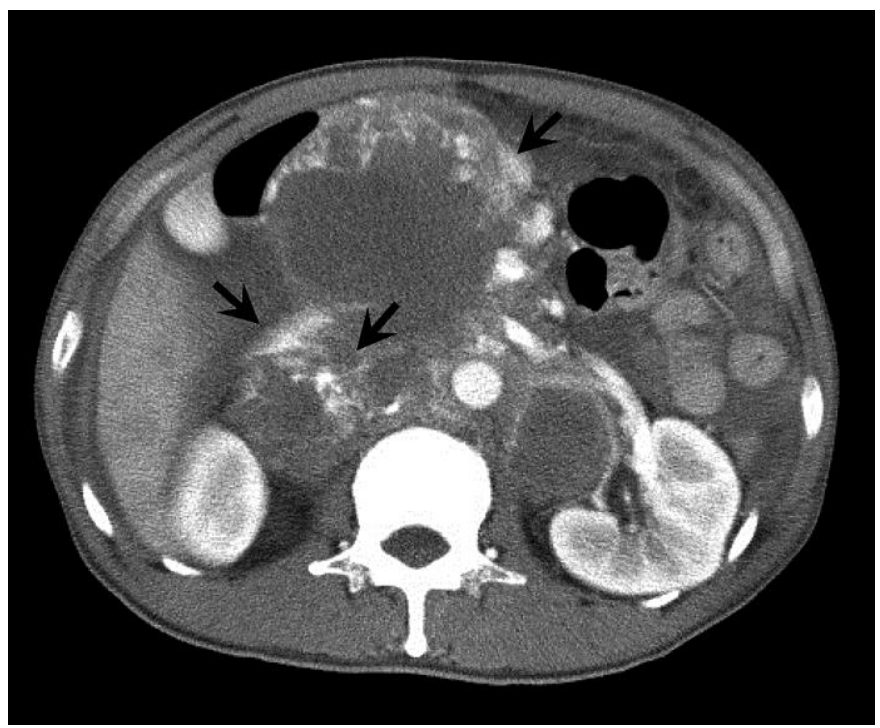

Fig. 2. An abdominal CT scan showed hemoperitoneum from a metastatic extragonadal germ cell tumor immediately before the emergency operation (black arrows).

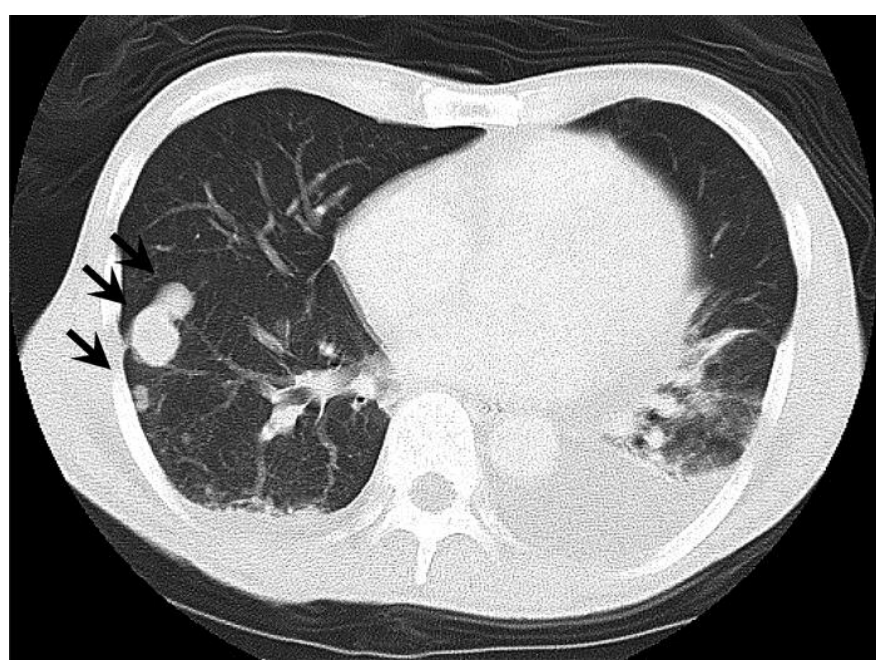

Fig. 3. A chest CT scan showed multiple lung metastases (black arrows). 


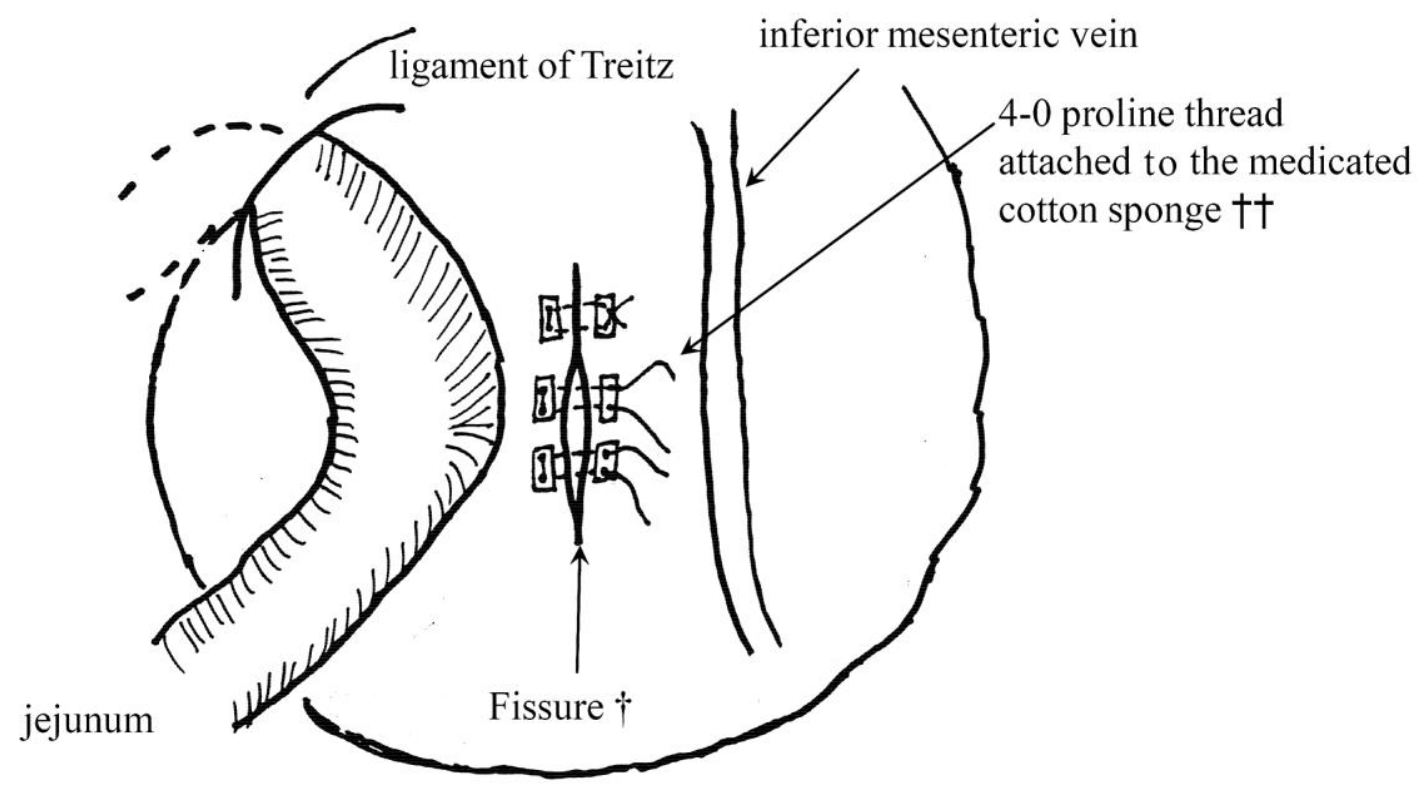

Fig. 4. The operative scheme showed that venous bleeding from the surface of a metastatic extragonadal germ cell tumor $(\dagger)$ was found between the ligament of Treitz and the inferior mesenteric vein in a horizontal position. Hemostatic treatment was performed with 4-0 proline thread attached to a medicated cotton sponge $(\dagger \dagger)$. 